\title{
Ein einziger Patient befeuerte die MERS-Epidemie
}

\author{
Wie bei SARS vor 14 Jahren wurde jetzt auch bei MERS in Südkorea ein Superverbreiter identifi- \\ ziert: Ein Mann hat wohl einen Großteil der Patienten angesteckt.
}

Sowohl das „severe acute respiratory syndrome“ (SARS) als auch das „Middle East respiratory syndrome“ (MERS) werden von Coronaviren verursacht.

Bei der SARS-Epidemie 2002/03 in China, Hongkong, Taiwan und anderen asiatischen Ländern waren etwa die Hälfte aller erfassten Fälle auf eine einzige Person zurückgegangen, einem sogenannten „Superspreader“.

Anhand von Kameraaufnahmen und Krankenakten haben Forscher nun belegt: Auch beim Mers-Ausbruch in Südkorea im Frühjahr 2015 gab es einen solchen Superverbreiter. Der Patient hat bei der südkoreanischen MERS-Epidemie gleich 82 Menschen mit dem MERS-Coronavirus (MERS-CoV) angesteckt. Das zeigt eine im Fachblatt „Lancet“ veröffentlichte Studie (Lancet 2016; online 8. Juli).

\section{"Superspreader" durch Kameraaufnahmen und Papierrecherche identifiziert}

Die Autoren rekonstruierten anhand von Kameraaufnahmen und Krankenakten den Epidemie-Verlauf im Samsung Medical Center in Seoul und identifizierten den sogenannten Superverbreiter: „Patient 14“, 35 Jahre alt, Bettnachbar des Patienten, der das Virus eingeschleppt hatte.

2015 war es zwischen Mai und Mitte Juli in Südkorea zum größten MERS-Ausbruch außerhalb des Nahen Ostens gekommen, 36 der insgesamt 186 Erkrankten starben. Mitgebracht hatte das Virus ein aus dem Nahen Osten heimkehrender 68-Jähriger. Nicht dieser „Patient $1^{\text {“ }}$ aber, sondern ein zeitweiser Bettnachbar habe besonders viele weitere Menschen angesteckt, berichten die Mediziner um Prof. Doo Ryeon Chung vom Samsung Medical Center. Die Männer hatten in einer Klinik in einem Zimmer gelegen, bevor klar wurde, dass der 68-jährige Mann mit MERS infiziert war. Der 35-Jährige habe dann kurz darauf die Klinik verlassen und die überfüllte Notaufnahme des Samsung Medical Center aufgesucht.

Binnen drei Tagen erfasste das Virus von diesem „Patient 14“ ausgehend 41 Besucher, 33 andere Patienten und 8 Krankenhausmitarbeiter. Das größte Ansteckungsrisiko hatten die Menschen im Umfeld, die sich für längere Zeit im selben Raum mit dem „Superspreader“ aufgehalten hatten: $20 \%$ von ihnen bekamen MERS.

\section{Virus stammt aus dem Nahen Osten}

Das MERS-CoV war erstmals im Jahr 2012 bei einem 60-jährigen Mann in Saudi-Arabien gefunden worden, der bald darauf an einer Pneumonie verstarb.

Seitdem wurde der Erreger nach Daten der Weltgesundheitsorganisation (WHO) bei mehr als 1.700 Menschen weltweit nachgewiesen, mehr als 600 von ihnen sind gestorben. Ein großer Teil der Infektionen wird nach Einschätzung von Experten aber wegen unspezifischer Symptome der Betroffenen gar nicht erkannt und damit auch nicht erfasst.
Typische Symptome der zunächst grippeähnlichen Erkrankung sind bei schwererem Verlauf Fieber, Atemprobleme, Pneumonie, Durchfall und Nierenversagen (mehr dazu im Fortbildungsbeitrag dieser Ausgabe). Das MERS-Virus gehört wie das SARS-Virus und viele Schnupfen- und Erkältungsviren zu den Beta-Coronaviren. An SARS waren 2002/03 binnen weniger Monate rund 800 Menschen gestorben, Tausende infizierten sich.

\section{"Superspreader" sind besonders infektiös}

Auch beim SARS-Ausbruch vor 14 Jahren ging ein großer Teil der Verbreitung auf einen einzelnen Mann zurück: einen Mediziner aus der südchinesischen Provinz Guangdong, der nach Hongkong reiste und - bereits schwer erkrankt - in einem Hotel eincheckte. Die WHO errechnet später, dass die Hälfte der rund 8.000 weltweit registrierten SARS-Fälle auf den Mann aus dem Hotel in Hongkong zurückgehen.

Solche Superverbreiter werden auch bei anderen Krankheiten vermutet: Sie setzen aufgrund bestimmter körperlicher Voraussetzungen besonders viele Viren frei und stecken darum auch besonders viele andere Menschen an.

Fabian Kretschmer

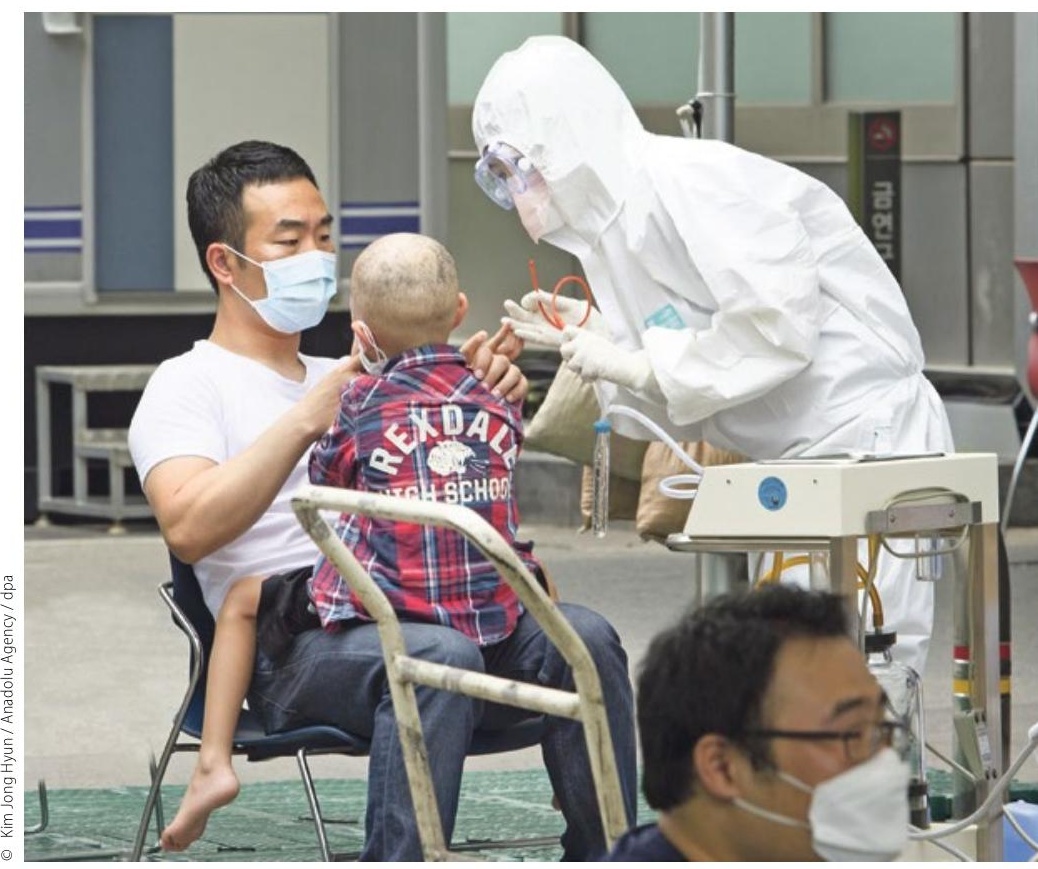

MERS 2015 in Südkorea: Eine Schwester im Schutzanzug untersucht Patienten in Quarantäne. 